\title{
Electrical characterization of defects introduced during sputter deposition of tungsten on $\boldsymbol{n}$ type $\mathbf{4 H}$-SiC
}

\author{
Shandirai M Tunhuma, M.J Legodi, J Nel, M Diale and F.D Auret \\ Department of Physics, University of Pretoria, Private Bag X20, Pretoria 0002, South Africa
}

\begin{abstract}
We have studied the defects introduced in $n$-type $4 H$-SiC during sputter deposition of tungsten using deep-level transient spectroscopy (DLTS). Current-voltage and capacitancevoltage measurements showed a deterioration of diode thermionic emission characteristics due to the sputter deposition. Two electrically active defects $E_{0.29}$ and $E_{0.69}$ were introduced. Depth profiling revealed that sputter deposition increases the concentration of the native $\mathrm{Z}_{1}$ defect. A comparison with prominent irradiation and process induced defects showed that the $\mathrm{E}_{0.29}$ was unique and introduced during sputter deposition only. The $\mathrm{E}_{0.69}$ may be silicon vacancy related defect.
\end{abstract}

\section{Introduction}

Silicon carbide has become an important material in the implementation of next generation photonics. It has been recently shown to harbor defects that have quantum functionality [1]. These defects have potential applications in the fields of quantum computation and cryptography. The technology is relatively simple and is being established on a platform of common industrial techniques that are already in existence such as ion implantation, particle irradiation and annealing [2]. In addition, $\mathrm{SiC}$ is a device friendly material with superior semiconductor properties such as a wide band gap and high dielectric background. It is therefore important to establish sound device fabrication protocols to be used in the device implementation.

Metallization is a crucial processing step in the semiconductor device manufacturing industry. Magnetron sputter deposition is arguably the most versatile technique for thin metal 
films. The technique is highly efficient because it can rapidly deposit metals with high melting points resulting in uniform films with good adhesion properties. It can be optimized to produce metal films with desired stoichiometric composition for particular purposes [3]. In some cases the technique has been used to enhance semiconductor properties [4]. Several types of nano-structures and films have been established on silicon carbide through sputtering [5, 6] It has been shown that the reaction kinetics involved are important in determining the thermodynamic stability of the films [7]

Due to the involvement of an incident plasma and metal particles, sputter deposition has been shown to introduce atomic scale surface damage which cause lattice distortions [8]. These impact the rectification properties of devices and in some cases introduce defects in the bandgap. In gallium, arsenide it has been shown that devices fabricated by sputter deposition have lower barrier heights which have been ascribed to introduction of donor like defects in the semiconductor during sputter deposition [9].

On the contrary, incident particles have also been used to engineer beneficial defects in $4 \mathrm{H}$ SiC [2]. Defect engineering has been employed in the past to optimize semiconductor material structures and for refined device control [10]. It is therefore important to investigate if the incident particles which emanate from the sputter deposition process can also be used to engineer advantageous defects.

In this paper we report on the defects introduced in n-type $4 \mathrm{H}$-SiC by sputter deposition of tungsten Schottky contacts. W contacts on $4 \mathrm{H}$-SiC are preferred for high temperature applications [11]. The defects introduced were compared to the prominent defects introduced in $4 \mathrm{H}$-SiC by incident ion irradiation such as from radionuclides. We also examined the prospects of using sputter deposition as a process for both metallization and defect engineering. 


\section{Experimental}

The $\mathrm{N}$ doped n-type $4 \mathrm{H}$-SiC wafers were obtained from Cree inc. Their active layers consisted of an epi-layer of net doping density $7 \times 10^{15} \mathrm{~cm}^{-3}$ grown on a highly doped substrate of $\sim 10^{18} \mathrm{~cm}^{-3}$. Smaller samples typically $5 \times 5 \mathrm{~mm}$ were cleaned by degreasing in boiling trichloroethylene, acetone and methanol, rinsing in deionized water and then etching using hydrofluoric acid. After rinsing again in deionized water, a $3000 \AA$ Ni Ohmic contact was deposited by resistive evaporation on the highly doped side in an Edwards Auto 306 vacuum chamber. Thereafter the samples were annealed at $950{ }^{\circ} \mathrm{C}$ in argon to allow for silicidation and to reduce contact resistance [12].

The cleaning procedure was repeated in an ultrasonic bath at room temperature. $0.6 \mathrm{~mm}$ circular tungsten Schottky contacts were deposited by dc magnetron sputtering on the epilayer at room temperature. The deposition was carried out under a dc power of $1000 \mathrm{~W}$ and an Ar pressure of approximately $2 \times 10^{-2}$ mbar. Target to sample distance was maintained at 7 $\mathrm{cm}$.

For control purposes Ni Schottky contacts were also fabricated on samples with the same ohmic contact as the sputtered ones following the same cleaning procedure. This is because resistive evaporation has been shown to not introduce defects in $4 \mathrm{H}$-SiC, as such these samples could allow for measurements on the native defects only [13].

DLTS spectra were recorded at a scan rate of $2 \mathrm{~K} / \mathrm{min}$ in the $15-360 \mathrm{~K}$ temperature range. At a quiescent reverse bias of $-5 \mathrm{~V}$, filling pulse amplitude of $1 \mathrm{~V}$ and filling pulse width of 1 ms.

Arrhenius analysis was done according to the equation 


$$
e_{n}=\sigma_{n}\left\langle v_{t h}\right\rangle \frac{g_{o}}{g_{1}} N_{c} \exp \left(-\frac{E_{c}-E_{t}}{k_{B} T}\right),
$$

which gives the emission rate as a function of temperature $T$, where $\left\langle v_{t h}\right\rangle$ is the thermal velocity of electrons, $\left(E_{c}-E_{t}\right)$ is the activation energy, $N_{c}$ is the density of conduction band states, $g_{0}$ and $g_{1}$ are the degeneracy terms referring to the states before and after electron emission and $k_{B}$ is the Boltzmann constant. Capture cross section is assumed to have a $T^{2}$ dependency, hence the $\log \left(e_{n} / T^{2}\right)$ versus $1000 / T$ plots.

In-order to investigate the thermal stability of the sputter deposition induced defects, the samples were isochronally annealed in the $100-600{ }^{\circ} \mathrm{C}$ temperature range in $100{ }^{\circ} \mathrm{C}$ incremental steps.

\section{Results and discussion}

In-order to evaluate the suitability of the fabricated contacts for DLTS, their quality was assessed using current-voltage $(I-V)$ and capacitance-voltage $(C-V)$ measurements. The Schottky-Mott rule was used to obtain $C-V$ barrier height $\left(\phi_{C-V}\right)$, and the carrier concentration $\left(N_{\mathrm{D}}\right)$ [14]. $N_{\mathrm{D}}$ was used to monitor carrier removal so that the accuracy of the DLTS measurements was not compromised through compensation of carriers [15]. Parameters for the $I-V$ characteristics in Figure 1 (ideality factor $(n), I-V$ barrier height $\left(\phi_{I-V}\right)$, and the reverse leakage current at -2 V) were determined using the thermionic emission (TE) model [16]. Table 1 shows the parameters obtained from the sputter deposition together with resistively evaporated samples.

From the results it was observed that sputter deposition results in contacts with poorer TE characteristics as confirmed by the lower barrier heights. This can be attributed to the exposure of the samples to an incident plasma together with the high energy incident particles during fabrication. It is well known that exposure of semiconductors to an incident plasma 
results in a change in surface stoichiometry due to the high kinetic energy of the impinging particles (compared to resistive evaporation) altering material structural properties and hence introducing electrically active defects close to the surface. This changes the position at which the Fermi level is pinned in some semiconductors which results in strong deviations in barrier height [17]. However the rectification properties of the measured devices were still suitable for DLTS measurements. The value of $N_{\mathrm{D}}$ was also comparable to the resistively deposited samples, therefore, the accuracy of the DLTS measurements was not compromised.

Figure 2 (a) shows the DLTS spectra obtained at a rate window of $80 \mathrm{~Hz}$. Curve (a) is the control spectrum obtained from $\mathrm{Ni} / 4 \mathrm{H}$-SiC Schottky barrier diodes fabricated using resistive evaporation. It shows the native $\mathrm{E}_{0.11}, \mathrm{E}_{0.13}, \mathrm{E}_{0.15}$ and $\mathrm{E}_{0.66}$ defects. The $\mathrm{E}_{0.66}$ is also known as the $\mathrm{Z}_{1}$ center and has been shown to have negative $\mathrm{U}$ behavior [18]. The $\mathrm{E}_{0.11}$ is a shallow nitrogen donor occupying a cubic lattice whereas the $\mathrm{E}_{0.13}$ and the $\mathrm{E}_{0.15}$ are attributed to titanium impurities [19].

Curve (b) shows the DLTS spectrum obtained after sputter deposition of tungsten Schottky contacts on n-type $4 \mathrm{H}$-SiC with the $\mathrm{E}_{0.11}, \mathrm{E}_{0.13}, \mathrm{E}_{0.15}, \mathrm{E}_{0.29}, \mathrm{E}^{{ }^{\prime}}{ }_{0.66}$ and the $\mathrm{E}_{0.69}$ peaks. It is clear that only the $E_{0.29}$ and $E_{0.69}$ result from the sputter deposition. The $E_{0.66}\left(Z_{1}\right.$ center) and has also been observed in $4 \mathrm{H}$-SiC exposed to high energy electrons [20]. This defect ( $\mathrm{Z}_{1}$ center) is an important defect in $4 \mathrm{H}$-SiC as it affects carrier lifetime to a considerable extent [21]. Different viewpoints exist in literature on its identity but it has been shown not to be dopant related [22]. The identity of the rest of the defects observed in this work is shown in Table 2. Arrhenius plots of the observed defects are shown in Figure 3 and the obtained signatures (activation energy and apparent capture cross section) are listed in Table 2

On spectrum (b), the peaks are observed to be sitting on a continuous skewed baseline. This baseline is detected in Laplace-DLTS measurements and inhibits accurate identification of 
defects as it contributes to background noise. A similar baseline has also been observed in heavy ion implanted GaN and alpha particle irradiated GaAs [23, 24]. It appears that the deposition process induces a continuum of defects at the surface of the silicon carbide which are detected as the baseline. This is evidenced by the inconsistent Laplace-DLTS spectra obtained from the baseline which gives inconsistent spectral density function peaks.

It has been reported that incident irradiation increases the concentration of the $\mathrm{Z}_{1}$ defect [25]. We used the fixed bias pulse variable pulse method to investigate the spatial distribution of the defect after irradiation. A marked increase in the defect concentration after sputter deposition was observed when compared to the resistive deposition samples (Figure 4). The defect concentration after sputter deposition shows an almost exponential decay with increasing depth. This could suggest that the defect is highly concentrated at the surface. It is worth noting that this defect concentration is now a summation of the concentration of the $E_{0.66}$ and the $E_{0.69}$ defects and not just resulting from the $E_{0.66}$. As such unless these defects are clearly split one cannot make any clear deductions about the actual concentration of the $\mathrm{Z}_{1}$ after any form of processing or irradiation.

The $\mathrm{E}_{0.29}$ defect is unique and has only been observed after sputter deposition in our samples. To the best of our knowledge it has not been previously reported in $4 H$-SiC. The defect is induced by heavy metal or gas ions that emanate from the sputter deposition process. We therefore propose that the defect may be a cluster or a complex of impurities. The introduction of the $\mathrm{E}_{0.69}$ close to the $\mathrm{E}^{{ }_{0.66}}\left(\mathrm{Z}_{1}\right.$ center$)$ has been attributed to interaction of the $\mathrm{Z}_{1}$ with irradiation which introduces an overlapping silicon vacancy $\left(\mathrm{V}_{\mathrm{si}}\right)$ transforming it into a complex [26]. This $\mathrm{V}_{\mathrm{Si}}$ formed after irradiation has been linked to the complexes formed after thermal treatment that can be employed as a single photon source [2, 27]. 
Identity of defects can be confirmed by the annealing behavior which should be consistent for any defect type. Thermal stability of the defects was investigated using isochronal annealing in the 100 - $600{ }^{\circ} \mathrm{C}$ temperature range. The annealing profiles are shown in Figure 4. Overall there is a general decrease in defect concentration with annealing temperature. It is clearly evident that most of the sputter damage anneals out by $300{ }^{\circ} \mathrm{C}$. Above $300{ }^{\circ} \mathrm{C}$ both the $\mathrm{E}_{0.39}$ and $\mathrm{E}_{0.69}$ cannot be detected by DLTS. The native defects continued to decrease in concentration with increasing temperature.

The DLTS spectrum obtained after annealing at $600{ }^{\circ} \mathrm{C}$ is shown in Figure 6. The $\mathrm{E}_{0.66}$ and $\mathrm{E}_{0.69}$ peak anneals out and becomes undetectable at $600{ }^{\circ} \mathrm{C}$. This was also observed by Ashgar et al, but they didn’t report a simultaneous introduction of the $\mathrm{E}_{0.39}$ [26]. $600{ }^{\circ} \mathrm{C}$ is the temperature at which the silicon vacancy has been reported to anneal out using DLTS [28]. This confirms that the $\mathrm{E}_{0.69}$ defect may be silicon vacancy related. This $\mathrm{V}_{\mathrm{Si}}$ formed after irradiation has also been shown to transform into the $\mathrm{C}_{\mathrm{Si}} \mathrm{V}_{\mathrm{C}}$ defect after thermal treatment at elevated temperatures which can be employed as a single photon source [2, 27]. We propose that sputter deposition may possibly be used simultaneously for both metallization and to induce these potentially beneficial defects.

\section{Conclusion}

We have investigated the electrical characteristics of Schottky barrier diodes fabricated on ntype $4 \mathrm{H}$-SiC using sputter deposition of tungsten. $I-V$ and $C-V$ measurements showed that the deposition had significant effects on the quality of the devices and resulted in relatively lower barrier heights and thermionic emission ideality factor. The results show that sputter deposition of $\mathrm{W}$ induces the $\mathrm{E}_{0.29}$ defect which is not introduced by other types of radiation or processing techniques. The defect may be a cluster or complex of impurities incident on the $4 \mathrm{H}$-SiC from the sputter deposition process. Sputter deposition also induced the $\mathrm{E}_{0.69}$. The $\mathrm{E}_{0.69}$ anneals out at $600{ }^{\circ} \mathrm{C}$ showing that it might be silicon vacancy $\left(\mathrm{V}_{\mathrm{si}}\right)$ related. Irradiation 
induced $\mathrm{V}_{\mathrm{si}}$ defects in $4 \mathrm{H}$-SiC have been linked to single photon sources in $4 \mathrm{H}$-SiC. We conclude that sputter deposition may be used for both metallization and to induce beneficial electrically active defects in $n-4 H$-SiC.

\section{Acknowledgements}

The authors gratefully acknowledge the financial support of the South African National Research Foundation and the University of Pretoria. Opinions, findings and conclusions in this publication are those of the authors and the NRF accepts no liability. 


\section{References}

[1] S. Castelletto, L. Rosa, B.C. Johnson, Silicon carbide for novel quantum technology devices, Advanced Silicon Carbide Devices and Processing; Saddow, S., La Via, F., Eds (2015).

[2] S. Castelletto, B. Johnson, V. Ivády, N. Stavrias, T. Umeda, A. Gali, T. Ohshima, A silicon carbide room-temperature single-photon source, Nature materials 13(2) (2014) 151156.

[3] H. Yeom, B. Maier, R. Mariani, D. Bai, S. Fronek, P. Xu, K. Sridharan, Magnetron sputter deposition of zirconium-silicide coating for mitigating high temperature oxidation of zirconium-alloy, Surface and Coatings Technology 316 (2017) 30-38.

[4] S.-H. Kim, G.-I. Shim, S.-Y. Choi, Fabrication of Nb-doped ZnO nanowall structure by RF magnetron sputter for enhanced gas-sensing properties, Journal of Alloys and Compounds 698 (2017) 77-86.

[5] L. Gou, C. Qi, J. Ran, C. Zheng, SiC film deposition by DC magnetron sputtering, Thin Solid Films 345(1) (1999) 42-44.

[6] H. Zhu, Q. Qi, L. Shi, SiC nanorods of highly preferred orientation prepared by radio frequency magnetron sputtering, Journal of Vacuum Science \& Technology B, Nanotechnology and Microelectronics: Materials, Processing, Measurement, and Phenomena 31(6) (2013) 060604.

[7] W.F. Seng, P.A. Barnes, Calculations of tungsten silicide and carbide formation on SiC using the Gibbs free energy, Materials Science and Engineering: B 72(1) (2000) 13-18.

[8] F. Volpi, A.R. Peaker, I. Berbezier, A. Ronda, Electrically active defects induced by sputtering deposition on silicon: The role of hydrogen, Journal of Applied Physics 95(9) (2004) 4752-4760.

[9] F.D. Auret, S.A. Goodman, Y. Leclerc, G. Myburg, C. Schutte, Electronic properties of defects introduced in GaAs during sputter deposition of gold Schottky contacts, Materials Science and Technology 13(11) (1997) 945-948.

[10] S.M. Tunhuma, F.D. Auret, M.J. Legodi, M. Diale, The fine structure of electron irradiation induced EL2-like defects in n-GaAs, Journal of Applied Physics 119(14) (2016) 145705.

[11] J. Rogowski, A. Kubiak, Effects of annealing temperature on the structure and electrical properties of tungsten contacts to n-type silicon carbide, Materials Science and Engineering: B 191 (2015) 57-65.

[12] P. Machac, B. Barda, P. Sajdl, Nickel ohmic contact on silicon carbide, 2006 International Conference on Advanced Semiconductor Devices and Microsystems, 2006, pp. 71-74.

[13] E. Omotoso, W.E. Meyer, S.M.M. Coelho, M. Diale, P.N.M. Ngoepe, F.D. Auret, Electrical characterization of defects introduced during electron beam deposition of $\mathrm{W}$ Schottky contacts on n-type 4H-SiC, Materials Science in Semiconductor Processing 51 (2016) 20-24.

[14] S.M. Sze, K.K. Ng, Physics of semiconductor devices, John wiley \& sons2006.

[15] M. Mikelsen, U. Grossner, J.H. Bleka, E.V. Monakhov, B.G. Svensson, R. Yakimova, A. Henry, E. Janzén, A.A. Lebedev, Carrier Removal in Electron Irradiated 4H and 6H SiC, Materials Science Forum, Trans Tech Publ, 2009, pp. 425-428.

[16] M. Grundmann, Physics of Semiconductors, Springer2010.

[17] A.G. Baca, C.I. Ashby, Fabrication of GaAs devices, IET2005.

[18] T.A.G. Eberlein, R. Jones, P.R. Briddon, Z1/Z2 defects in 4HSiC, Physical Review Letters 90(22) (2003) 225502 1-4. 
[19] E. Omotoso, W.E. Meyer, F.D. Auret, S.M.M. Coelho, P.N.M. Ngoepe, Electrical Characterization of Defects Introduced in n-Type N-Doped 4H-SiC during Electron Beam Exposure, Solid State Phenomena 242 (2015) 427-433.

[20] A.T. Paradzah, E. Omotoso, M.J. Legodi, F.D. Auret, W.E. Meyer, M. Diale, Electrical Characterization of High Energy Electron Irradiated Ni/4H-SiC Schottky Barrier Diodes, Journal of Electronic Materials (2016) 1-6.

[21] N.T. Son, X.T. Trinh, L. Løvlie, B. Svensson, K. Kawahara, J. Suda, T. Kimoto, T. Umeda, J. Isoya, T. Makino, Negative-U System of Carbon Vacancy in $4 \mathrm{H}-\mathrm{SiC}$, Physical review letters 109(18) (2012) 187603.

[22] L. Storasta, A. Henry, P. Bergman, E. Janzén, Investigations of possible nitrogen participation in the Z1/Z2 defect in $4 \mathrm{H}-\mathrm{SiC}$, Materials Science Forum, Trans Tech Publ, 2004, pp. 469-472.

[23] S. Tunhuma, F. Auret, M. Legodi, M. Diale, Electrical characterisation of $5.4 \mathrm{MeV}$ alpha-particle irradiated; low doped, n-type gallium arsenide.

[24] P.J. van Rensburg, F. Auret, V. Matias, A. Vantomme, Electrical characterization of rare-earth implanted GaN, Physica B: Condensed Matter 404(22) (2009) 4411-4414.

[25] C.G. Hemmingsson, N.T. Son, A. Ellison, J. Zhang, E. Janzén, Negative-U centers in 4H silicon carbide, Physical Review B 58(16) (1998) R10119-R10122.

[26] M. Asghar, I. Hussain, H.S. Noor, F. Iqbal, Q. Wahab, A.S. Bhatti, Properties of dominant electron trap center in n-type $\mathrm{SiC}$ epilayers by means of deep level transient spectroscopy, Journal of Applied Physics 101(7) (2007) 073706.

[27] M. Bockstedte, A. Mattausch, O. Pankratov, Ab initio study of the annealing of vacancies and interstitials in cubic SiC: Vacancy-interstitial recombination and aggregation of carbon interstitials, Physical Review B 69(23) (2004) 235202.

[28] A. Kawasuso, F. Redmann, R. Krause-Rehberg, M. Weidner, T. Frank, G. Pensl, P. Sperr, W. Triftshäuser, H. Itoh, Annealing behavior of vacancies and Z1/2 levels in electronirradiated 4H-SiC studied by positron annihilation and deep-level transient spectroscopy, Applied Physics Letters 79(24) (2001) 3950-3952.

[29] A. Castaldini, A. Cavallini, L. Polenta, F. Nava, C. Canali, C. Lanzieri, Deep levels in silicon carbide Schottky diodes, Applied Surface Science 187(3) (2002) 248-252.

[30] T. Dalibor, G. Pensl, T. Yamamoto, T. Kimoto, H. Matsunami, S. Sridhara, D. Nizhner, R.P. Devaty, W.J. Choyke, Oxygen-Related Defect Centers in 4H Silicon Carbide, Materials Science Forum, Trans Tech Publ, 1998, pp. 553-556. 
Table 1: Diode parameters of Schottky diodes on $4 \mathrm{H}$-SiC fabricated by sputter deposition of tungsten and by resistive evaporation of nickel (control)

\begin{tabular}{|c|c|c|c|c|c|c|}
\hline Samples & $\begin{aligned} & n \\
\pm & 0.01\end{aligned}$ & $I_{s} \times 10^{18} \pm 0.01(\mathrm{~A})$ & $R_{\mathrm{s}} \pm 2(\Omega)$ & $N_{\mathrm{D}} \times 10^{15} \pm 0.1\left(\mathrm{~cm}^{-3}\right)$ & $\Phi_{\mathrm{IV}} \pm 0.02(\mathrm{eV})$ & $\Phi_{\mathrm{CV}} \pm 0.02(\mathrm{eV})$ \\
\hline Resistive evaporation & 1.03 & 1.04 & 47 & 7.3 & 1.25 & 1.27 \\
\hline Sputter deposition & 1.47 & 4.12 & 29 & 7.9 & 0.91 & 0.60 \\
\hline
\end{tabular}


Table 2: Electronic properties of defects in as deposited W/n-4H-SiC Schottky barrier diodes fabricated by sputter deposition observed at $V_{\mathrm{R}}=-5.0 \mathrm{~V}, V_{\mathrm{P}}=$ $0.5 \mathrm{~V}$ and $t_{\mathrm{p}}=1 \mathrm{~ms}$.

\begin{tabular}{lcccc}
\hline Defect label & Energy $\pm 1(\mathrm{meV})$ & $\sigma_{\mathrm{n}} \pm 1 \%\left(\mathrm{~cm}^{-2}\right)$ & Defect ID & Similar defects \\
\hline $\mathrm{E}_{0.11}$ & 110 & $1.5 \times 10^{-11}$ & $\mathrm{~N}$ impurity & {$[13,19,20]$} \\
$\mathrm{E}_{0.13}$ & 130 & $1.9 \times 10^{-14}$ & Ti impurity & {$[13,20]$} \\
$\mathrm{E}_{0.15}$ & 145 & $2.5 \times 10^{-16}$ & Ti impurity & {$[13,20,29]$} \\
$\mathrm{E}_{0.29}$ & 294 & $1.2 \times 10^{-15}$ & - & This work \\
$\mathrm{E}_{0.66}^{\prime}$ & 660 & $3.7 \times 10^{-15}$ & $\mathrm{~V}_{\mathrm{si}},\left(\mathrm{Z}_{1} / \mathrm{Z}_{2}\right)$ & {$[20,26,30]$} \\
$\mathrm{E}_{0.69}$ & 693 & $6.0 \times 10^{-15}$ & $\mathrm{~V}_{\mathrm{c}},\left(\mathrm{Z}_{1} / \mathrm{Z}_{2}\right)$ & {$[18-20]$} \\
\hline
\end{tabular}




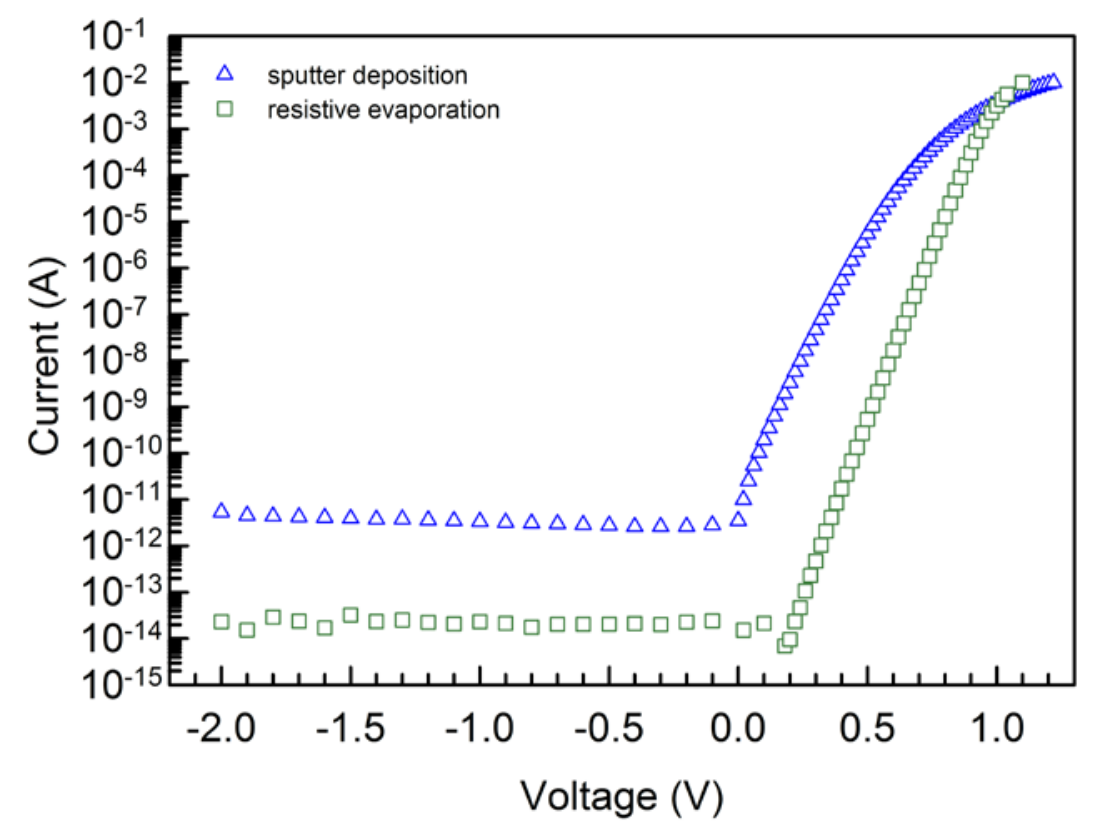

Figure 1: $I-V$ characteristics of Schottky barrier diodes fabricated on $4 H$-SiC with resistive evaporation and sputter deposition

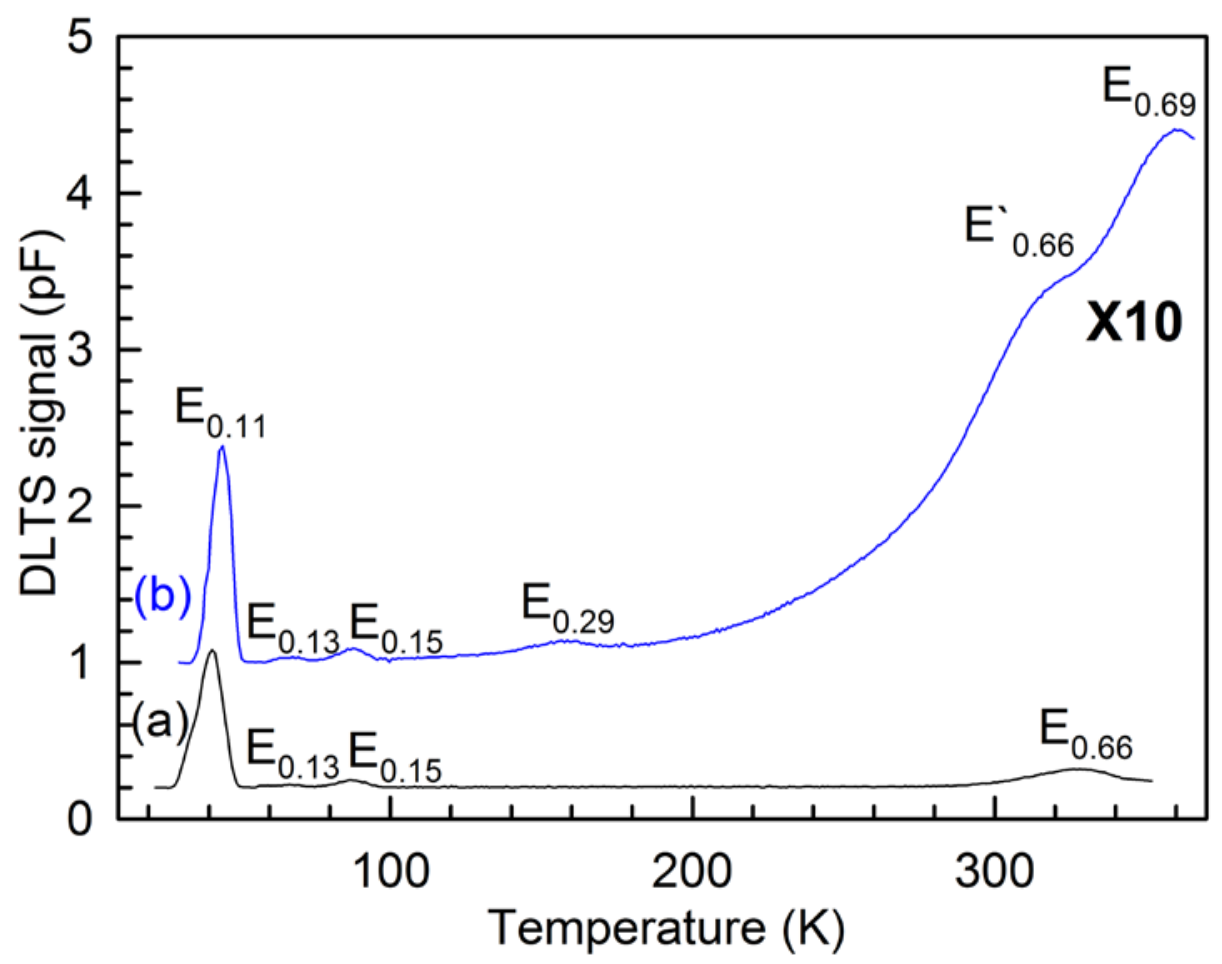

Figure 2.DLTS spectra of (a) the control spectra obtained from $\mathrm{Ni} / 4 \mathrm{H}$-SiC Schottky barrier diodes fabricated by resistive evaporation (b) W/4H-SiC 
Schottky barrier diodes fabricated by sputter deposition (magnified 10 times) observed at $V_{\mathrm{R}}=-5.0 \mathrm{~V}, V_{\mathrm{P}}=0.5 \mathrm{~V}$ and $t_{\mathrm{p}}=1 \mathrm{~ms}$.

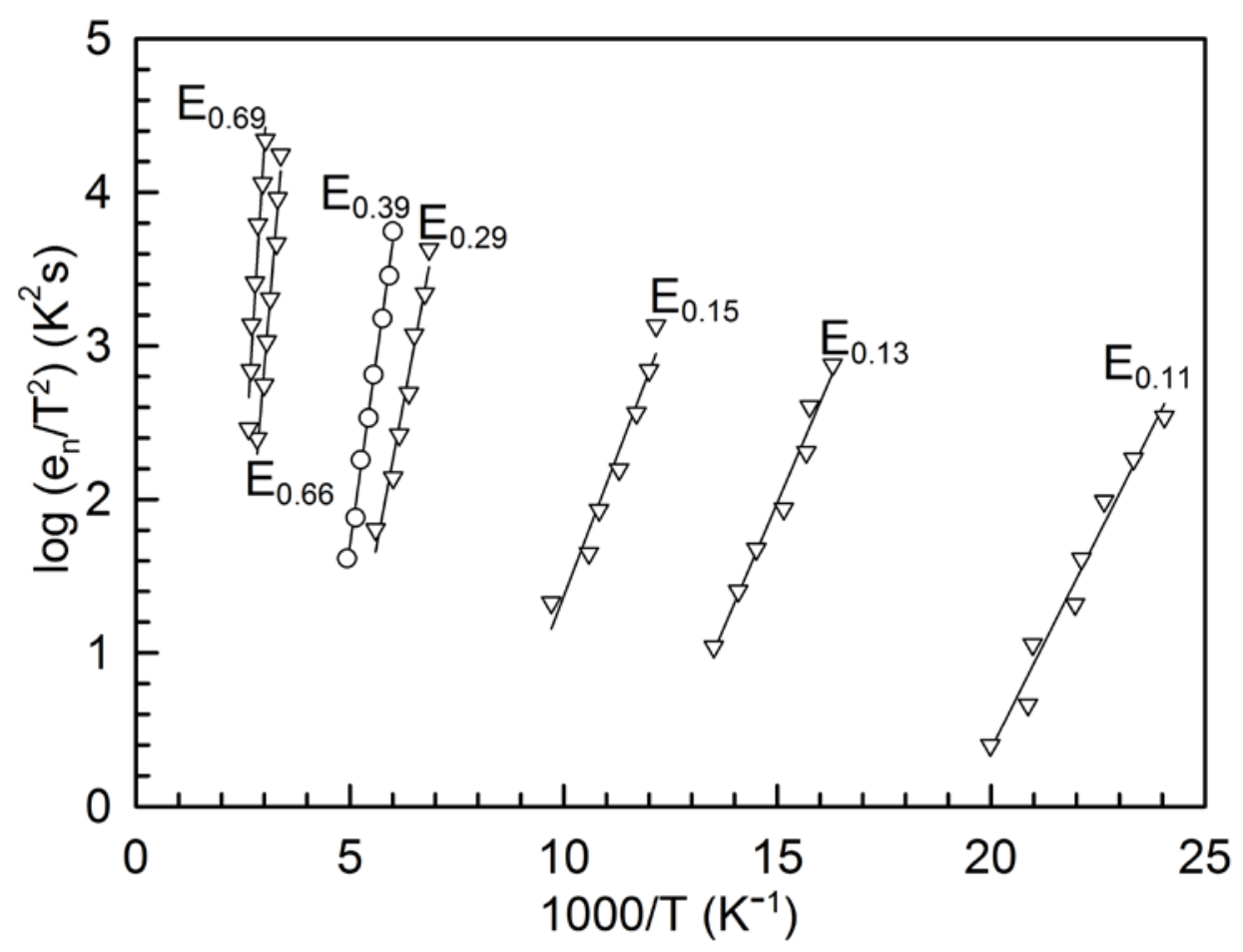

Figure 3. Arrhenius plots for defects introduced by sputter deposition of $\mathrm{W}$ in $4 \mathrm{H}$-SiC. The $\left(\mathrm{E}_{0.39}\right.$ is observed after annealing at $\left.600{ }^{\circ} \mathrm{C}\right)$ 


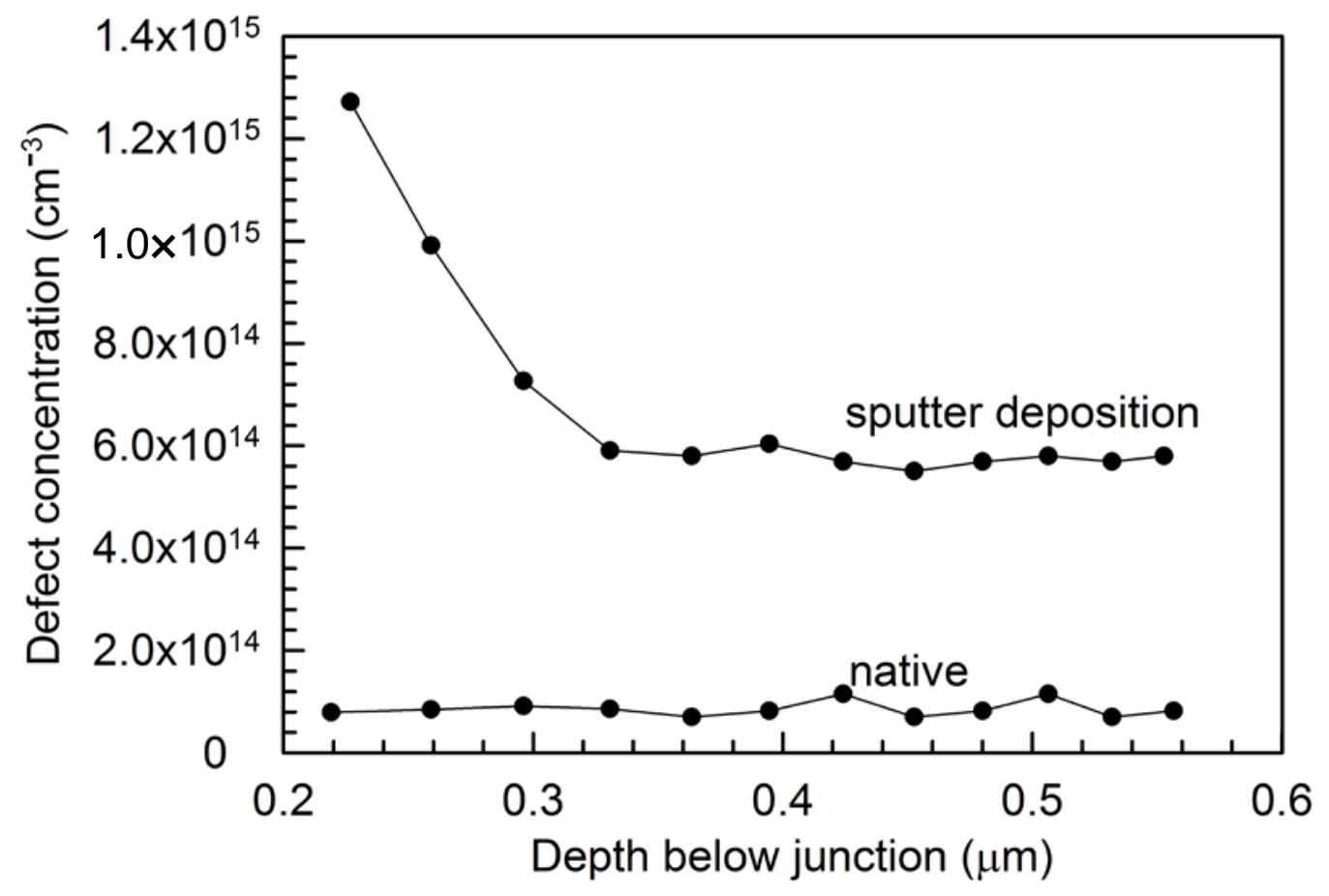

Figure 4.Depth and concentration of the $\mathrm{E}_{0.66}$ defect in W/4H-SiC Schottky barrier diodes fabricated by sputter deposition compared to control samples (fabricated by resistive evaporation) measured at $320 \mathrm{~K}$. 


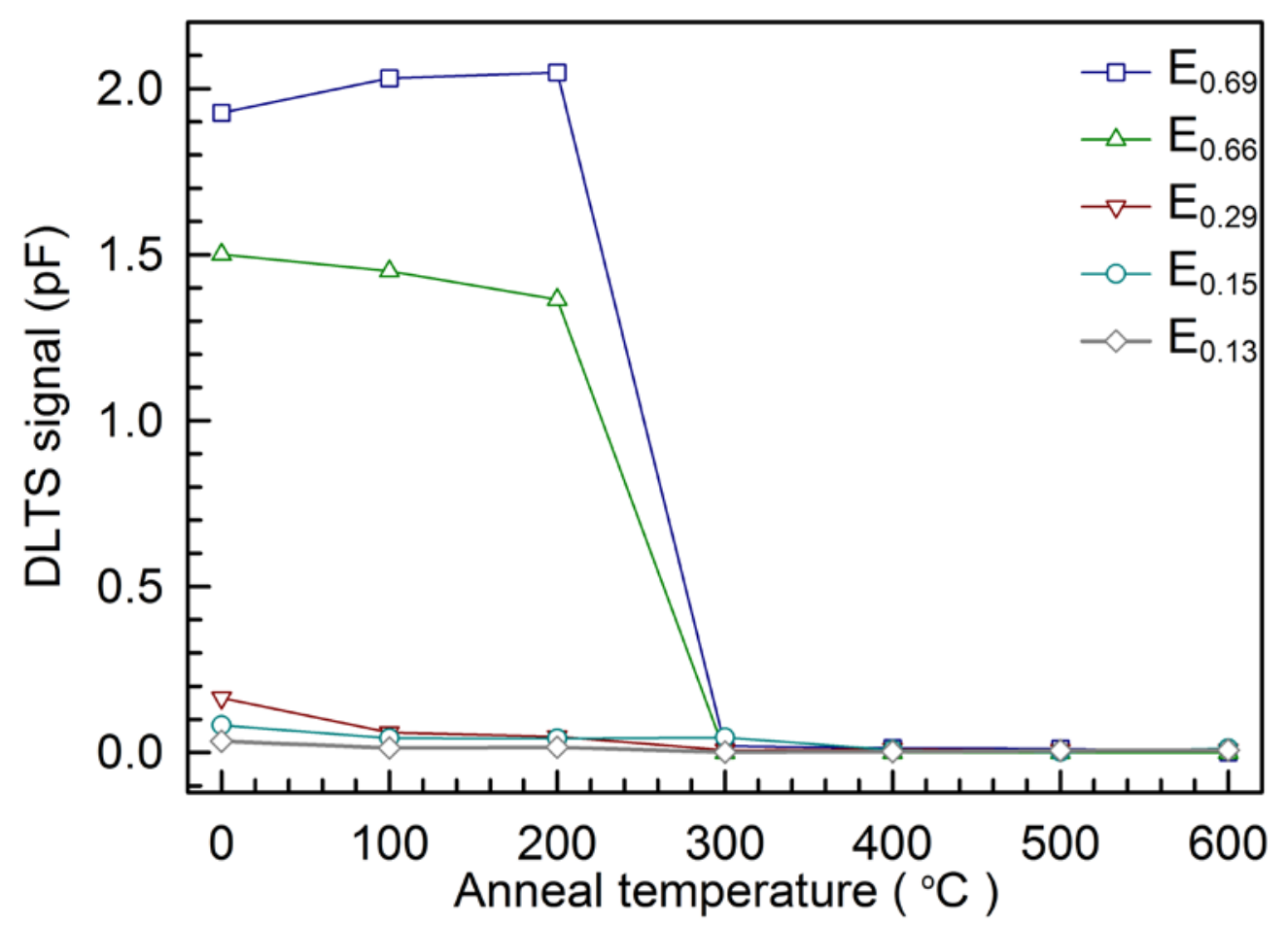

Figure 5. Isochronal annealing (15 minute periods) of native and tungsten sputter deposition induced defects in $n$-type $4 H$-SiC 


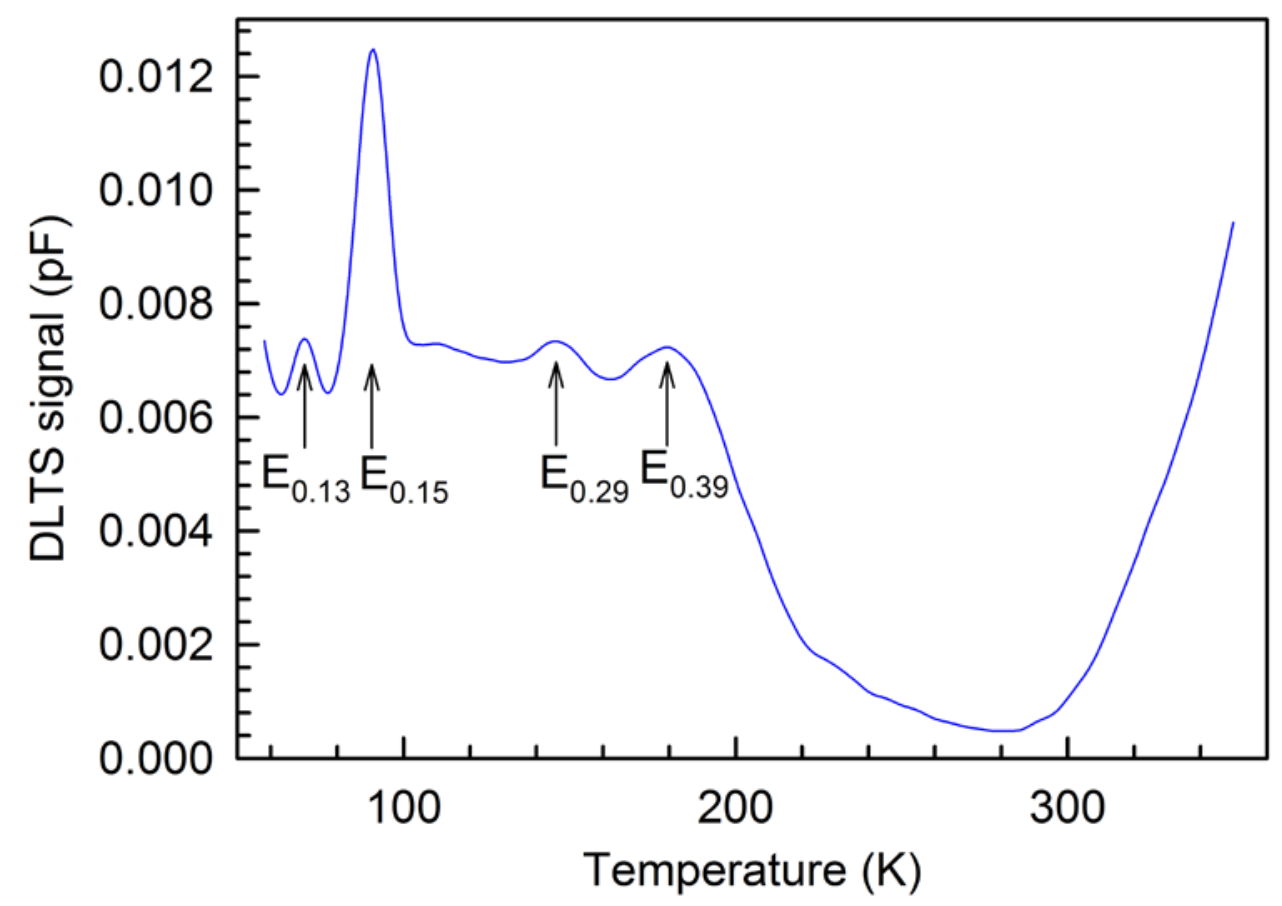

Figure 6. DLTS spectra of W/4H-SiC Schottky barrier diodes fabricated by sputter deposition after annealing at $600{ }^{\circ} \mathrm{C}$ observed at $V_{\mathrm{R}}=-5.0 \mathrm{~V}, V_{\mathrm{P}}=0.5$ $\mathrm{V}$ and $t_{\mathrm{p}}=1 \mathrm{~ms}$. 